\title{
Cybersemiotic Systemic and Semiotical Based Transdisciplinarity
}

\author{
Brier, Søren
}

\author{
Document Version \\ Final published version \\ Published in: \\ Transdisciplinary Journal of Engineering \& Science
}

DOI:

$10.22545 / 2019 / 0119$

Publication date:

2019

License

CC BY

Citation for published version (APA):

Brier, S. (2019). Cybersemiotic Systemic and Semiotical Based Transdisciplinarity. Transdisciplinary Journal of Engineering \& Science, 10. https://doi.org/10.22545/2019/0119

Link to publication in CBS Research Portal

\section{General rights}

Copyright and moral rights for the publications made accessible in the public portal are retained by the authors and/or other copyright owners and it is a condition of accessing publications that users recognise and abide by the legal requirements associated with these rights.

\section{Take down policy}

If you believe that this document breaches copyright please contact us (research.lib@cbs.dk) providing details, and we will remove access to the work immediately and investigate your claim.

Download date: 26. Apr. 2023

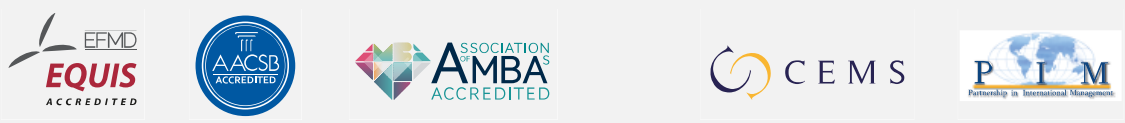




\section{Se ThelTLAS \\ Cybersemiotic Systemic and Semiotical Based Transdisciplinarity}

SØren Brier, Dept. of Management, Society and Communication, Copenhagen Business School, Denmark, E-mail: sbr.msc@cbs.dk

Received 2 January, 2019; Revised 27 February, 201913 March, 2019

Copyright (C)2019 SØren Brier. This is an open access article distributed under the Creative Commons Attribution License (https://creativecommons.org/licenses/by/4.0/), which permits unrestricted use, distribution, and reproduction in any medium, provided the original work is properly cited.

Available online 15 March, 2019 at www.atlas-journal.org, doi: 10.22545/2019/0119

\begin{abstract}
1 transdisciplinary theory of cognition and communication based on the process self-organizing and autopoietic system theory of Niklas Luhmann integrated with a triadic semiotic paradigm of experience and interpretation with phenomenological and hermeneutical aspects of C.S. Peirce, goes beyond info-computationalism in its integrating of phenomenological and hermeneutical aspects of Peircean semiotic logic with a cybernetic and autopoietic systemic emergentist process view. This makes the emergence of mind and transdisciplinary view of sciences possible.
\end{abstract}

Keywords: Cybersemiotics, Transdisciplinary models, Luhmann's system theory, info-computationalism, Peircean triadic semiotics.

\section{Introduction}

The pursuit of a transdisciplinary evolutionary view of the sciences going beyond mechanicism and dualism has always been essential to systems theory and cybernetics, even though they have their origin in the natural and technical sciences. Therefore - like the logic positivist and their attempt of constructing a unity of science - they have severe problems of integrating qualitative sciences like phenomenology and hermeneutics $[1,2]$ as well as semiotics in their attempts to become truly transdisciplinary. It is the unsolved problem of a theory of mind, which includes qualia [3] that is a vital aspect of the problem. Furthermore even if that is solved, then there is still the problem if a science of experiential mind and meaningful communication beyond the quantitative and logical view of mechanistic science is possible at all $[4,5]$. Bertalanffy $[6]$ as well as Wiener [7] wanted to go beyond mechanicism. They both saw that the mechanical materialistic form of ontology that lies behind classical physics describes the cosmos as consisting of absolute abstract laws. Mechanistic science also denies the existence of experiential subjective consciousness and free will as having any causal influence on behavior and cognitive processes. That is paradoxical as experience and meaning based on natural language are prerequisite for any science, no matter how much it escapes into mathematics $[8$, 
9]. The problem is that there is no widely accepted definition of embodied social meaning in contrast to - Shannon or Wiener information. That makes the finding of formal semantic theory of information as difficult as defining an objective theory of information going beyond computer technology that does not include an embodied producer and receiver. It is my hypothesis that what we need is to enlarge our philosophical foundation with a realist semiotic process theory that can support a transdisciplinary scientific search for truth and a logic that encompasses embodied meaning.

\section{How to Formulate the Problem}

In order to be able to work with qualitative subjectivity and meaning production, we often see mechanicism being part of a dualism combining a mind independent world and a mental world. This ontology has pretty much been our common sense view in the West [10] since the start of the Enlightening period, when we strived to make the subjective more rational. However, concepts like "meaning," "truth," "intentionality," and "knowledge" still do not have a rigorous explanation in traditional logic. They are part of another paradigm, the qualitative phenomenological and hermeneutical one as long as we re are in a dualistic ontology or a pure materialism. Yet, there is an intuitive sense in which information is related to semantic content and meaning. So it is still a challenge to make sense of this semantic component, though it is the most central for humans.

This dualist mechanical view came into conflict with the spread of evolutionary cosmological ideas in physics and modern biology. This was because the mechanical model seems unable to encompass the view of evolution as a foundation process in a reality; which both physics and biology established as foundational for the scientific worldview. This role was then taken over by Thermodynamics [11].

The physical basis for this move was partially realized by Prigogine \& Stengers [11] through nonequilibrium thermodynamics and in their break with the mechanical physics as the most basic physics to the advantage of non-equilibrium thermodynamics $[12,13]$ and much later Smolin [14]. The latter inspired by Peirce - was promoting the idea of emergent developing laws manifesting as the universe develops and becomes more complicated. These chances in foundation of the sciences were support- ing general systems theory and cybernetics holistic and self-organizing view of a scientific description of evolution. However, there was still the problem of mind.

In cybernetics, McCulloch developed the idea of the brain as a logical computer [15] leading into cognitive science and from there into the info-computation view that sees the nature, the brain, society, and the human as material computational entities; the brain being the hardware and the experiential mind as a product of the software a kind of language of thought behind the natural language. Even though Bateson 16] expanded this to his ecology of mind, cybernetics never created a full-blown phenomenological theory of the experiential mind to get out of the cybernetic information concept of form and matter.

Thus, we have various attempts at describing cognition and communication from a transdisciplinary point of view in a material world:

1. Info-mechanical processing with matter-energy and objective information as basic stuff of the world to which all cognition and communication is to be reduced. It is usually a realistic paradigm [17, 18] striving to go beyond the Turing Computer. This view leaves out the conscious observer as the cause of experiences who can detect differences and make certain differences more important than others. Communication is seen as the transfer of objectively measured bits of information (further explained in [19]).

2. Constructivist approaches are developed by human beings with an experiential focus, which combines models on meaning and reality by give up realism for the sake of a dynamic relativism focusing on power and ideology instead of truth (further explained and discussed in [20]). Thus, paradigms 1 and 2 are not compatible.

3. A general systems and cybernetic view with emergence theory attempting to solve this problem through a theory of systems according to which the latter are more than the sums of their parts and in it self-organizations owns the possibility of qualitative emergence [21]. Still, we have no knowledge of a theory of qualitative emergence from matter, energy, and information to experience. Qualitative emergence is a nice idea but it does not really have a scientific basis. 
4. Luhmann's integration of autopoietic second order cybernetic, Bateson's cybernetic mindecology [16] and general systems theory [22] make the individuality of systems a function of their self-limiting and self-organizing character through internal negative feedback systems. This production of closure though autopoiesis creates individuality and agency in biological, psychological, and socio-communicative systems, making objective information transfer alone impossible without any structural couplings. It is Luhmann, [23] that creates this triple autopoiesis theory. However, even structural couplings cannot count as interpretations because experiential cognition is not theoretically grounded in the theory. Nagel [24] also criticizes Neo-darwianan theory of evolution for lacking the theoretical foundation to be able to explain the evolution of mind in living systems. Qualitative interpretation and communication is simply not theoretically addressed in cybernetics and systems, be it in Bateson $[16,25]$ or Maturana \& Varela [26, 27]. There is no phenomenological and hermeneutical foundation in the theories. It is not clear why Bateson's mind [25] or Maturana and Varela's biological autopoiesis [27] or Luhmann's [28] triple autopoiesis (biological, psychological, and social) should have any experiential awareness aspect, as the foundation of the cybernetic theory of mind is purely functionalistic. A combination of cybernetic, systemic and semiotic understandings of the semiotics of information, cognition and communication area seems therefore crucial to the development of a systemic Cybersemiotics that can support teaching and human development, because cybernetics and systems have not develop a theory of the origin of forms of meaning and qualia.

A Peircean view of reality includes both mind and matter as existing in the form of a complex network of continuous adaptive morphological forms or triadic sign functions. For Peirce view of logic is exceptional in that he consider logic to be semiotics "Logic is the study of the essential nature of signs. A sign is something that exists in replicas" (Peirce EP 2:310). ${ }^{1}$ It means that Peircean semiotic produces a philosophy and scientific theory of signs meaning

\footnotetext{
${ }^{1}$ In according with tradition reference to W, EP1 and 2, RTL, HL , NEM, MS and $\mathbf{R}$ are to: Peirce, C. S.
}

and materiality. A sign is an immanent dynamic producer of forms of signification manifesting in concrete signs like the letter 'e'. A sign is a type that manifest in tokens, as there are many e-replicas on the page, but only one sign [29].

Peirce saw philosophy as the most general Branch of applied mathematics and the first discipline of philosophy as phenomenology. He agreed with Husserl that the first thing a philosopher should do was to was to study the most general aspects of experience and from here try to extract the most general call categories [30]. Peirce in his phenomenologically and mathematically grounded philosophy was searching for a different way to establish those foundational categories that were so crucial to Aristotle's, Kant's and Hegel's philosophies [29]. After much work [31] he ended up with three basic categories: the monad, the dyad and the triad. Peirce invented or produced a completely new list of categories [32] as the foundation of his phenomenologically and mathematically founded semiotics of logics.

When we talk about relational logic then its foundation is 1 . The non-relative or singly relative, 2 . The dual, and 3. The triple or polyadic relatives. Peirce simply called them Firstness, Secondness, and Thirdness. He determined Firstness phenomenologi-

(1992). Peirce, Charles S., Writings of Charles S. Peirce: A Chronological Edition, Vols. 1-6 and 8, ed. (1981-2010) Peirce Edition Project, Bloomington: Indiana University Press.[W1-W6, W8]. Peirce, Charles S., Collected Papers, InteLex electronic edition reproducing Vols. I-VI (ed. Charles Hartshorne and Paul Weiss, Cambridge, MA: Harvard University Press, 1931-1935), and Vols. VII-VIII (ed. Arthur W. Burks, same publisher, 1958). [CP 1-8] [CP. Vol and paragraph] Peirce, Charles S., Houser, N. and Kloesel, C(ed.) (1992).The Essential Peirce: Selected Philosophical Writings, Vol. 1, Bloomington: Indiana University Press. [EP1]. Peirce, Charles S., ed. Peirce Edition Project (Ed.) (1998). The Essential Peirce: Selected Philosophical Writings, Vol. 2 (Bloomington: Indiana University Press). [EP2]. Peirce, Charles S., ed. (1997) Turrisi, P. A. Pragmatism as a Principle and Method of Right Thinking, study edition of the 1903 Harvard Lectures on Pragmatism (Albany: State University of New York Press)[HL].Peirce, Charles S., ed. (1992) Ketner, K. L. Reasoning and the Logic of Things, the Cambridge Conferences Lectures, with introduction and commentary by Ketner and Hilary Putnam (Cambridge, MA: Harvard University Press). [RLT]. Peirce, C.S. The New Elements of Mathematics; [NEM] v indicates volume number, $p$ page number. MS and R: Peirce's manuscripts unpublished in book or article form, transcriptions or facsimiles of them available on the internet identified by MS number. Most scholars use the MS numbers assigned by Richard Robin, sometimes preceded by "R" instead of "MS". 
cally as the basic feeling of qualities be it different colors, sounds or tastes. Secondness is the experience of resistance be it of matter or another mind, and Thirdness is the mediation between Firstness and Secondness aspects into the habit and understanding, the basis of his hermeneutics as a non-dual transdisciplinary paradigm.

Remark that he did not start in matter and energy as the basis aspect of ontology, but in (unexplained) raw experience. Here is a quote from one of the texts where Peirce shortly describes his three categories.

[...]by the "mode of being" of anything can be meant only the kinds of characters which it has, or is susceptible of taking, corresponding to the three kinds of characters, there must be three categories of things: first, those which are such as they are regardless of anything else, like the living consciousness of a given kind of feeling, say of red; secondly, those which are such as they are by virtue of their relation to other things, regardless of any third things, which is the case with the existence of all bodies, whose reality consists in their acting on each other, in pairs; thirdly, those which are such as they are by virtue of bringing two others into relation, as signs of all sorts are such only so far as they bring their significance to bear upon the objects to which they are applied.

(EP 2.427-428; 1907)

The idea is that that the universal forms of experience must correspond to the universal forms of thinking [30]. It is important to understand that in Peircean transdisciplinarity reality is not only material; it also includes possibility or (would-bees). $\mathrm{He}$ is very close to Popper's [33] propensity theory of chance. They both have the view that chance is real [34]. For Peirce the mind and social and communicative reality is as an important aspect of reality as matter and energy. Actually, Luhmann [22] in his autopoietic system theory also sees the social as communication. Peirce's triadic reasoning and dynamic ontology $[29,35,36]$ and logic of relatives [37] goes far beyond what John Archibald Wheeler [38, 39] and Wheeler \& Ford [40] developed through the scientific based philosophy of "It from bit", where information in the form of bits or even qubits at the quantum level is the most fundamental level of reality (discussed in more detail in [41, 42]). Ontologically, Wheeler's idea is that a quantum level existing below ordinary physical matter consists of information. Thus, information is in this philosophy ontologically more basic than matter and energy. It is the organizing aspect of the physical world. Matter is created from information (it from bit).

However, that does not explain the experiential mind either. Therefore, quantum neurophysiology has been developed and Penrose \& Hameroff [43] have worked for many years to develop a quantum model of how the brain produces consciousness. Their theory is an alternative to computational mind $[44,45]$. Computational mind in the form of AI has not produced conscious experience in the form of qualia that seems ubiquitous for embodied living systems' way of producing or reflecting conscious awareness. Neither natural nor computational sciences have been able to explain mind from matter, even though the quantum world do seems to go far beyond our common sense world. Recently, Thomas Fuchs [46] has written a much needed book: Ecology of the Brain: The phenomenology and biology of the embodied mind, which attempts to reformulate the whole problem through integrating a phenomenological grounding in a dynamic, evolutionary, and ecological view of the brain, in an attempt to break out of the mind-brain dualism with a mechanistic basis into a non-dual process view. As Peirce's point is:

No modern science is the study of the material, but of the immaterial contained in the material. Once men were contended with facts, and names, now, we always ask What is the meaning of this thing? Now the meaning of a thing is what it conveys.

(Peirce W 1:50)

Within Peircean semiotic ontology information is what a sign comes to carry in acts of semiosis. Semiosis becomes more fundamental than information, which does not exist prior to or apart from the sign that contains it. Information can therefore not be ascribed to objects that are not signs. To Peirce, semiosis is not only something that goes on in language, but is the transdisciplinary phenomenon that connects, nature, mind, and culture. 
I define a sign as anything which is so determined by something else, called its Object, and so determines an effect upon a person, which effect I call its interpretant, that the later is thereby mediately determined by the former.

A sign is an action of mediation within the modes of being and organizations of mind as matter: "The one intelligible theory of the universe is that of objective idealism, that matter is effete mind, inveterate habits becoming physical laws." (Peirce: CP 6.25). In that view, Peirce was close to Hegel's objective idealism, but even more to Schelling's philosophy, though differs from both of them in his empiricist semiotic borne fallibilist belief in that the self-corrective empirical testing carry our hypothesis in science towards greater truth [1].

Peirce - who was one of the pioneer developer of logical algebras $[47,48]$ - uses his triadic process philosophy to produce a general transdisciplinary triadic dynamic model of representation and signification. Here is one of his formulations:

In every genuine Triadic Relation, the First Correlate may be regarded as determining the Third Correlate in some respect; and triadic relations may be divided according as that determination of the Third Correlate is to having some quality, or to being in some existential relation to the Second Correlate, or to being in some relation of thought to the Second for something. A Representamen is the First Correlate of a triadic relation, the Second Correlate being termed its Object, and the possible Third Correlate being termed its Interpretant, by which triadic relation the possible Interpretant is determined to be the First Correlate of the same triadic relation to the same $\mathrm{Ob}-$ ject, and for some possible Interpretant.

(Peirce, EP 2:290; 1903)

Olshewsky [49] describes in a very short and precise way how this phenomenological, triadic semiotics constructs a bridge from perception through signbased thinking and non-linguistic communication to language starting with the Firstness of immediate experience:
Phenomenological, nothing exists in the immediate present, which is pure possibility. This immediate firstness, to be actualized, must interact with a second, becoming part of an existent past, and can only be made intelligible by a third to interpret it. An interpreted event presupposes continuity and generality, and thus has implication for the future. It is by virtue of this implicative character that a meaningful even becomes a sign (text) to an interpreter. Thus even the most rudimentary and immediate experience must be semiotically informed to be consciously perceived. There is no thought without signs, and thirdness seeps into perception at every pore. On the other hand, thirdness is ontologically constrained by the limits of secondness and firstness.

(Olshewsky [49])

From this triadic relation logic Peirce built up the dynamic process-model of the sign. Peirce's philosophy of semiosis is a realism that is not a materialism and not a systems theory (it is before systems theory), though it can integrate one. It is a process philosophy of the non-dual continuum of mind and matter. Peircean objective idealism is a synechism, as it posits a world of infinite continuity. It is also a Tychism as its ontology posits a world of continuing activity. It has these two aspects in common with modern quantum field theory (Brier, $1997 \mathrm{a}+\mathrm{b}$ ) and, like physics, cybernetics, and systems, it has a main focus on form. Peirce wrote:

... there are two sorts of connection which do not involve anything but Matter and Form; namely, the determination of Matter by Form, and the blind reaction of Matter with Matter.

There are, however, forms of connexion of which this is not true. Such is the action of a sign in bringing its interpreter into relation with its object. Indeed, if we fully set before ourselves all that is involved in this action, we shall see that signification, meaning the action of a sign, covers all connexions of this description ... the very entelechy of reality is of the nature of a sign. One can hardly glance down a printed page without seeing a number of things, or individual objects, determined like this: the. 
These "replicas," as I shall call them, embody one and the same word. This one word is not an individual object. No more is it a thought, if by a "thought" be meant an individual act of the mind. Not being individual, it is not Matter. Nor is it, properly speaking, Form. For instead of being what it is of itself, and remaining altogether such as it is even if not connected with matter, the sign's mode of being is, on the contrary, such that it consists in the existence of replicas destined to bring its interpreter into relation to some object. A Form is a quality or character.

(Peirce NEM 4:297)

In Peircean triadic semiotics, semiosis is a relational dynamics that defines the basic process of mind becoming matter as 'instantiations'. Our universe is produced by a type-token dynamism going far beyond the conceptual linguistic human sociocommunicative realm into the biological as well as physical-chemical aspects of realty [42]. For Peirce, the universe and its laws are evolving out of a "pure" "Zero" or emptiness in a vision close to quantum field physics, but still different from it with is basis in phenomenology [50-54]. Inspired by Aristotle, Peirce calls the directional force that drive semiosis to develop into self-correcting systems for entelechy:

This Entelechy, the third element which it is requisite to acknowledge besides Matter and Form, is that which brings things together

(Peirce NEM 4:295)

It is pretty close to the force of self-organization in general system theory, which you find as central in Laszlo' books [55-57]. Peirce's philosophy is not only producing an epistemology and a transdisciplinary philosophy of science but also a connection to a trans-religious spiritual philosophy [58].

The difficulty of getting Peircean semiotic production of meaning accepted is that it works on a triadic logical basis, where cybernetics and cognitive science share a dyadic form of logic with Saussurean semiology and its view of language as a system. But semiology lacks an empirical connection between the semiotic system and the rest of reality as it only works with signifier and signified in a system of differences with no direct referral to empirical reality ([59] for further argumentation).

However, Peirce's view of logic and semiotics is much more realistic and naturalistic in its universality than structuralist semiology. This is achieved empirically by a fallibilist use of signs, -of which only some are words - to form hypotheses and then to determine a fallible but consequential truth through a hypothetical - deductive method. Peirce added nadic relations to Boolean algebra in 1870, introduced quantifiers in 1880, and extended the algebraic notation to both first-order and higher-order logic in 1885. Peano adopted Peirce's algebra and changed some of the symbols to create the modern notation for predicate calculus. In 1896, Peirce invented existential graphs (EGs) as a more diagrammatic notation for "the atoms and molecules of logic", with a method that addresses the semantic issues of logic in a way that can be transferred to any notation. [36], because Peirce considered graphs as more diagrammatic than any linear notation. But he saw that there could never be a perfect way of representing continuity and therefore he produced many variations of Existential Graphs (EG).They are a diagrammatic system of logic by means of which, we can express, and then examine and experiment with, statements and inferences.The EG-system was invented by Charles S. Peirce in 1896, and, as developed by him, and it soon became a complete and consistent treatment of elementary logic. Still, Peirce is better known in traditional logic for his logical algebras and his pioneering work in the logic of relations [60].

More than a century ago, Peirce argued that there are unanalyzable three-place relations, and a relationally complete logic requires not only monadic and dyadic relations, but genuine triadic relations. A genuine triadic relation is a relation, which cannot be analyzed into combinations of relations of any smaller acidities. Genuine triadic relations are three-relata relations. It is a commonplace of contemporary logic that there are no indecomposable triadic relations. However, as one of the major pioneers of the algebra of logic, Peirce contended that, besides monadic and dyadic relations, a relationally complete logic must also have genuine triadic relations that cannot be analyzed into combinations of relations of lesser adicity to be able to model the simple relational function of A giving B to C. Furthermore, these three-forms can be combined to all 
higher order forms and therefore suffice for a complete logic of relations. But for Peirce, logic is not a part of a transcendental divine rationality as the old Greeks in classical time thought (Logos). He - on the contrary - views logic as rooted in the social principle and in contrast to the Turing-based info-computationalism, he views the social principle as rooted in logic. As a consequence of this pragmaticist process philosophy Peirce views logic as semiotic and as the normative science of the right way of reasoning. This view is foundational for the communicative ethics of Habermas philosophy [61]. Peirce wrote about this relational logic:

The letters of the alphabet will denote logical signs. Now logical terms are of three grand classes. The first embraces those whose logical form involves only the conception of quality, and which therefore represent a thing simply as "a." These discriminate objects in the most rudimentary way, which does not involve any consciousness of discrimination. They regard an object as it is in itself as such (quale); for example, as horse, tree, or man. These are absolute terms. The second class embraces terms whose logical form involves the conception of relation, and which require the addition of another term to complete the denotation. These discriminate objects with a distinct consciousness of discrimination. They regard an object as over against another, that is as relative; as father of, lover of, or servant of. These are simple relative terms. The third class embraces terms whose logical form involves the conception of bringing things into relation, and which require the addition of more than one term to complete the denotation. They discriminate not only with consciousness of discrimination, but with consciousness of its origin. They regard an object as medium or third between two others that is as conjugative; as giver of - to -, or buyer of - for - from -. These may be termed conjugative terms. The conjugative term involves the conception of third, the relative that of second or other, the absolute term simply considers an object. No fourth class of terms exists involving the conception of fourth, because when that of third is introduced, since it involves the conception of bringing objects into relation, all higher numbers are given at once, inasmuch as the conception of bringing objects into relation is independent of the number of members of the relationship.

(Peirce: CP 3.63)

In Peirce's contention, the triadic function develops its morphological result by connecting relations, which are encoded spatial, temporal, and modal measurements, within that transformational act [62]. In Peirce's view, pure mathematics is the science of necessary reasoning about hypothetical possibilities. Rephrasing Taborsky, she suggests that one can view the three Peircean modal categories as referring to the quality of information.

Peirce sees Firstness as a mode of potentiality. Information in this mode is potential but not actual. Contrary to this, Secondness is defined as a mode of individual actuality. Information in this mode exists in a discrete and individual morphology - what Bateson [16] called a difference that makes a difference. Thirdness is defined both as a mode of generality, as habits and rules and other forms of necessity. Information in this mode exists as knowledge, understood as a substratum of normative conventions. It is a non-local mode and functions within both the internal and external zones. In short potential, actual, and necessary information.

Contrary to the info-computational view as well as cybernetics and systems relying on information as a fundamental concept, Peircean semiotic view starts out from a phenomenological ground for considering meaningfully interpreted cognition and communication [63], and combines this with pure qualitative mathematics. His pragmaticism [64], functions as a theory of determining the meaning of a concept or a model [65]. Luhmann's systems theory and Peirce's semiotics have in common that information can only exists as part of a meaningful message whose informational contents are determined by the differences in knowledge between sender and receiver/interpreter.

But the concept of experiential meaning is not theoretically and philosophically represented in systems and cybernetics. On the other hand, semiotics is in need of a systems as well as cybernetic utopoiesis theory that takes into account the dynamism and self-organizing character of embodied systems' closure. Therefore, the integrated approach of Cybersemiotics is suggested as an enlargement to 


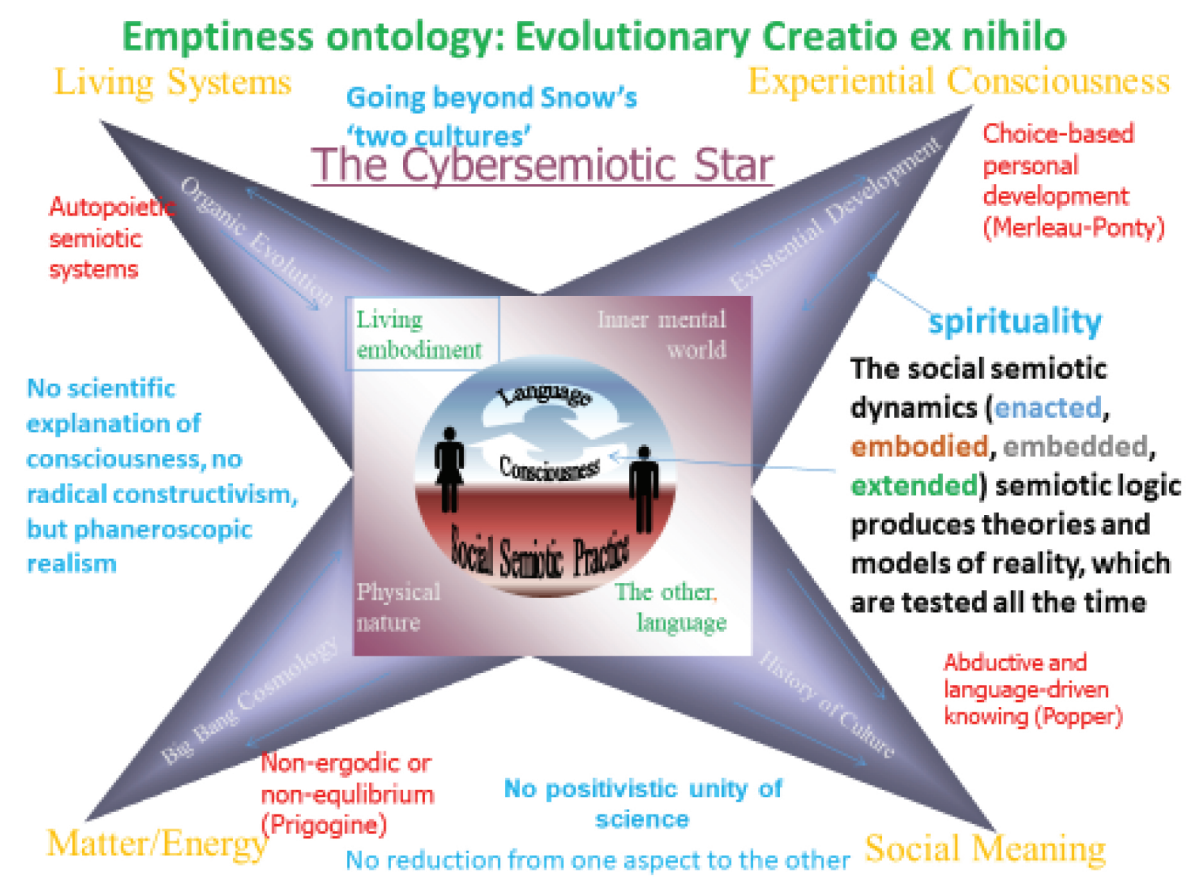

Figure 1: The cybersemiotic Star [21]The red arrows going out from the center are illustrating theoretical predictions that can be tested empirically. Arrows going back towards the center illustrates test result such as falsifications going back to force changes in theories. The center is where the embodied semiotic minds interact in language born socio-cultural practices that develops a cultures take on reality including an anthropology and a spirituality. It is an ongoing learning process on many levels as Bateson [25] has described.

Peircean semiotics, which can make it able to deal with an embodied way of handling these aspects of logical reasoning $[63,2]$ because reasoning, for Peirce, is purposeful continuity of inferences and he understands logic as being semiotic.

\section{Transdisciplinary Paradigms}

Cybersemiotics attempts to combine a cyberneticsystemic and a semiotic view to amend the shortcomings of the above described transdisciplinary models to include theories of experiential embodied consciousness and meaningful communication in encompassing the area of the qualitative sciences. It does so by on one hand turning them into a model that is neither mechanistic in a totalitarian way nor confined to an algorithmic or physicalistic reductionism, and one the other hand does not lapse into a constructivist relativism by giving up all scientific truth claims. I have made a graphical model to in order to make a one view possibility of the model (See Figure 1).

Cybernetics and systems sciences attempt to overcome these problems by means of their dynamic theory of emergence, according to which new qualities arise through the development of systems as in dialectical materialism or when two types of systems are integrated. From the materialism or infocomputationalism that dominates the natural and technical sciences ontology today the emergence of mind is a mystery. On hand, if matter were without mind, it would probably be chaotic pure low energy, not able to find its form as matter when the habits of the universe became law-like. On the other hand, what if we accepted constructivism as a pragmatic fact as in the hypothetical deductive method? It is us who creates the theories and scientific vocabulary to make explanatory theories world, and then accept a fallibilist realism like the philosophies of science developed by Popper [66] and Peirce, where we empirically test the theories, with only the possibility of proving them wrong. Thus, it is through meaningful and embodied semiotic and linguistic interaction with material, psychological and social reality that we create culture as a hypothesis of how the world's processes function. I suggest that, with regard to processes of embodied cognition and communication, the knowledge we cultivate falls into in four main 
areas: Firstly, the outer world often called nature, where one may further distinguish between a dead and a living part. Secondly, our view of the living part takes its start from the experience of our own bodies and empathy with other embodied beings and their ability to have bodily experiences of pleasure and pain. The third area comprises meaningful aspects like experiences and imaginations such as storytelling and phantasies, which in turn lead into the fourth area of communication and culture, where many of these stories are enacted and re-negotiated in concrete social contexts. Peirce wrote about the dynamics of the interaction of form and matter in the middle of the model to bring forth the four worlds:

We see that by the action of reason and will, that is, by the action of a sign, matter becomes determined to a Form; and we infer that wherever Matter becomes determined to a Form it is through a sign. Much that happens certainly happens according to Natural Law; and what is this Law but something whose being consists in its determining Matter to Form in a certain way? ...

\section{(Peirce, NEM 4:299-300)}

Cybersemiotics consists in suggesting a semiotic pragmaticist theory that takes its start from those contexts of social communication from which we create science (as 'the given') in the first place. In the model abductively produced explanations flow from the center towards the points of the star out towards the surroundings, where our theories can be falsified by the way things actually are - no matter what we think about them, as Popper and Peirce each suggest in their philosophies of science. However, the model also gives up the belief in the final verification of any piece of general scientific knowledge. The model does not work with any simple reductionist explanations - be they from physics, biology, phenomenology, or social constructivism (any of the points of the star). So, there is no reduction from culture to life or matter. As Peirce wrote, "I hold that truth's independence of individual opinions is due (as far as there is any "truth") to it being the predestined result to which sufficient inquiry would ultimately lead." (CP 5.494). His semiotic process philosophy shares with Prigogine's non-equilibrium thermodynamics as well as cybernetics and systems that it is a process philosophy of irreversible time in nature, life, mind, and culture, which contrary to mechanical physics considers the so-called 'laws of nature' to be emergent 'habits of nature', which manifest as the universe develops from nothingness [67, $68,13,14]$. Peirce's semiotic world view has Tychism in common with systems theory and cybernetics and dialectical materialism as well as dialectical idealism (Hegel) in that there is a basic random dynamic at the basic micro level as we also see it in modern quantum field theory, where all the spontaneous dynamism is in the vacuum field's virtual particles [69]. The theory's most famous non-technical explanation is Hawking [70].

The problem is that, as long as these different scientific paradigms do not have background philosophies that include experiential mind and meaningful communications, they cannot really connect evolution and ecology with human and cultural development, without producing a scientist explanation that is not a real philosophy. The reason is, that it is lacking an anthropological foundation that is consistent with its belief in that a group of humans - called scientists - is able to know the truth about aspects of the world. However, as Bruno Latour [71] claims with the title: We have never been modern, we have never been able to separate nature and culture really, as is also obvious from Peirce's synechism or logic of continuity [72]. As a concrete example, we can look at the so-called ecological crisis. What we consider natural landscapes are most often cultural products of our views of nature. That of course means that the ecological crisis is a cultural crisis. It is our problem as a culture that the honey bees as well as the majority of insects and therefore the birds in nature are dying off at accelerating rates.

So for Peirce, what information theory of Shannon \& Wiener defines as bits, Bateson defines as differences that makes a difference, and Maturana \& Varela claims has to be part of a structural coupling for an autopoietic system to put any signification on differences, Peircean biosemiotics says that when a difference is able to make a difference on a living system - as a species - then it is the definition of a sign. The difference is an object that is interpreted to have significance for the survival or pleasure of the species, or individual as part of a culture, its survive and flourishing human welfare.

Funding: This research received no external funding.

Conflicts of Interest: The author declare no con- 
flict of interest.

\section{References}

[1] Daube-Schackat, R. (1996). Peirce and hermeneutics. In T. M. Olshewsky \& V. M. Colapietro (Eds.). Peirce's doctrine of signs (381-414). Berlin/New York, NY: de Gruyter Mouton.

[2] Feil, S. \& Olteanu, A. (2018). Abduction, hermeneutics, and the interpretation of interpretation, human arenas. https://doi.org/10.1007/s42087-018-0013-y

[3] Kim, J. (1998). Mind in a physical world: An essay on the mind-body problem and mental causation. Cambridge, MA: The MIT Press.

[4] Kim, J. (2005). Physicalism, or something near enough. Princeton, NJ: Princeton University Press.

[5] Brier, S. (2015). Finding an information concept suited for a universal theory of information. Progress in Biophysics \& 3 Molecular Biology, 119, 622-633.

[6] Bertalanffy, L. von, (1969). General system theory. New York: George Braziller,

[7] Wiener, N. (1965/1948). Cybernetics or control and communication in the animal and the machine (2nd ed). New York, NY: The MIT Press and John Wiley \& Sons.

[8] Bohr, N. (1949). Discussions with Einstein on epistemological problems in atomic physics. In P. A. Schilpp (Ed.). The library of living philosophers (pp. 199-241), Volume 7. Albert Einstein: PhilosopherScientist. Open Court.

[9] Kafatos, M. C. \& Kato, G. C. (2017). Sheaf theoretic formulation for consciousness and qualia and relationship to the idealism of non-dual philosophies. Progress in Biophysics and Molecular Biology, 131, 242-250.

[10] Klawonn, E. (2009). Mind and death. Odense: University Press of South Denmark.

[11] Prigogine, I. \& Stengers, I. (1984). Order out of chaos: Man's new dialogue with nature. New York, NY: Bantam Books.

[12] Prigogine, I. (1980). From being to becoming. San Francisco, CA: W.H. Freeman.

[13] Prigogine, I. (1996). The end of certainty: Time, chaos, and the new laws of nature. New York, NY: The Free Press.

[14] Smolin, L. (2013). Time Reborn: From the Crisis in Physics to the Future of the Universe. Boston: Houghton Mifflin Harcourt.

[15] Dupuy, J.-P. (2009). On the origin of cognitive science. Cambridge, MA: The MIT Press.
[16] Bateson, G. (1973). Steps to an ecology of mind: Collected essays in anthropology, psychiatry, evolution and epistemology. St Albans: Paladin.

[17] Dodig-Crnkovic, G. (2017). The info-computational nature of morphological computing. In V. C. Mller (Ed.), Studies in applied philosophy, epistemology and rational ethics. In Philosophy and Theory of Artificial Intelligence, pp 115-123, Book series; Sapere 5 . Berlin: Springer.

[18] Chaitin, G. (2006). Epistemology as information theory. Collapse, 1, 27-51.

[19] Brier, S. (2015). Finding an information concept suited for a universal theory of information. Progress in Biophysics \&3 Molecular Biology, 119, 622-633.

[20] Brier, S. (2009). Cybersemiotic Pragmaticism and Constructivism. Constructivist Foundations, 5, 1938.

http://www.univie.ac.at/constructivism/journal/ articles/5/1/019.brier.pdf

[21] Brier, S. (2008).Cybersemiotics: Why information is not enough. Toronto: Toronto University Press.

[22] Luhmann, N. (1995). Social systems. Stanford, CA: Stanford University Press.

[23] Luhmann, N. (1989). Ecological communication. Cambridge, UK: Polity Press.

[24] Nagel, T, (2012). Mind and cosmos: Why the materialist neo-darwinian conception of nature is almost certainly false. Oxford, UK: Oxford University Press.

[25] Bateson, G. (1980): Mind and nature: A necessary unity. New York: Bantam Books.

[26] Maturana, H., \& Varela, F. (1980). Autopoiesis and cognition: The realization of the living. London: D. Reidel.

[27] Maturana, H., \& Varela, F. (1986). Tree of knowledge: Biological roots of human understanding. London: Shambhala.

[28] Luhmann, N. (1986). The autopoiesis of social systems. In F. Geyer \& J. van der Zouwen (Eds.), Sociocybernetic paradoxes (pp. 172-192). London: Sage.

[29] Burch, R. W. (1991). A Peircean reduction thesis: The foundation of topological logic. Lubbock, TX: Texas Tech University Press.

[30] Harsthorne, C. (1964). Charles Peirce's "one contribution to philosophy" and his most serious mistake. In E. C. Moore \& R. S. Robin (Eds.), Studies in the philosophy of Charles Sanders Peirce (455-474). Amherst, MA: University of Massachusetts.

[31] Esposito, J. L. (1980). Evolutionary metaphysics: The development of Peirce's categories. Athens, OH: Ohio University Press. 
[32] Peirce, C. S. (1868). A new list of categories. Proceedings of the American Society of Arts and Sciences, 7, 287-298.

[33] Popper, K. R. (1990). A world of propensities. Bristol: Thoemmes.

[34] Gillies, D. (2016). The propensity interpretation. In A. Hájek \& C. Hitchcock (Eds.), The Oxford handbook of probability and philosophy. Oxford: Oxford University Press.

[35] Sowa, J. F. (1999). Signs, processes, and language games: Foundations for ontology. (Extended version of an invited lecture presented in May 1999 at the International Conference on the Challenge of Pragmatic Process Philosophy at the University of Nijmegen).

[36] Sowa, J. F. (2013). From existential graphs to conceptual graphs. International Journal of Conceptual Structures and Smart Applications, 1, 39-72.

[37] Peirce. C. S. (1873). Description of a notation for the logic of relatives, resulting from an amplification of the conceptions of Boole's calculus of logic, Memoirs of the American Academy of Arts and Sciences, Vol. $9,317-378$.

[38] Wheeler, J. A. (1990). Information, physics, quantum: The search for links. In W.H. Zurek (Ed.), Complexity, entropy and the physics of information (Santa Fe Institute Studies in the Sciences of complexity vol. 8) (3-29). Santa Fe, NM: Westview Press.

[39] Wheeler, J. A. (1994). At home in the universe. New York, NY: Am. Institute of Physics Press.

[40] Wheeler, J. A. \& Ford, K. (1998). Geons, black holes, and quantum foam. New York, NY: W.W. Norton Company.

[41] Brier, S. (2017). Peircean cosmogony's symbolic agapistic self-organization as an example of the influence of eastern philosophy on western thinking. Progress in Biophysics and Molecular Biology 131, 22-107.

[42] Brier, S. (2017). How Peircean semiotic philosophy connects Western science with Eastern emptiness ontology. Progress in Biophysics and Molecular Biology, 131, 377-386.

[43] Penrose, R. \& Hameroff, S. (2011). Consciousness in the universe: Neuroscience, quantum space-time geometry and "Orch OR" theory. Journal of Cosmology, 14.

[44] Penrose, R. (1989). The emperor's new mind: Concerning computers, minds, and the laws of physics. Oxford: Oxford University Press.

[45] Penrose, R. (1995). Shadows of the mind: A search for the missing science of consciousness, London: Oxford University Press.
[46] Fuchs, T. (2017). Ecology of the brain: The phenomenology and biology of the embodied mind. Oxford: Oxford University Press.

[47] Ketner, K. L. (1986). Peirce's “most lucid and interesting paper": An introduction to cenapythagoreanism. International Philosophical Quarterly, 26, 375-392.

[48] Johnson-Laird, P. N. (2002). Peirce, logic diagrams, and the elementary operations of reasoning. Thinking and Reasoning, 8, 69-95.

[49] Olshewsky, T. M (1996). The construction of Peircean hermeneutics. T. M. Olshewsky \& V. M. Colapietro(Eds.) Peirce' Doctrine of Signs (441-449). Berlin: de Gruyter Mouton.

[50] Cahoone , L. (2009). Arguments from nothing: God and quantum cosmology. Zygon, 44, 777-796.

[51] Brier, S. (2014). Pure zero. In T. Thellefsen \& B. Srensen (Eds.), Charles Sanders Peirce in his own words: 100 years of semiotics (pp. 207-212). Series: Semiotics, Communication and Cognition [SCC] 14. New York: De Gruyter Mouton.

[52] Brier, S. (2014). The riddle of the Sphinx answered: On how C. S. Peirce's transdisciplinary semiotic philosophy of knowing links science, spirituality and knowing. In C. Tandy (Ed.), Death and anti-death, Volume 12: One hundred years after Charles S. Peirce (1839-1914). Ann Arbor, MI: Ria University Press.

[53] Brier, S. (1997). Cyber-semiotics: On autopoiesis, code-duality and signgames as vital aspects of biosemiotics. pp. 913-916 In I. Rauch \& G. F. Carr (Eds.), Semiotics around the world: Synthesis in diversity. Proceedings of the Fifth Congress of the International Society for Semiotic Studies, Berkeley, 1994 (pp. 913-916). New York: Mounton de Gruyter.

[54] Brier, S. (1997). Cybersemiotics: A paradigm integrating, second order cybernetics with the triadic semiotics of C. S. Peirce and Wittgenstein's pragmatic language game theory to a transdisciplinary theory of the self-organization of meaning. Revue de la pensée d'aujourd'hui, vol. 25-7. (In Japanese)

[55] Laszlo, E. (1995). The interconnected universe, conceptual foundations of transdisciplinary unified theory. Singapore: World Scientific.

[56] Laszlo, E. (1996). The whispering pond: A personal guide to the emerging vision of science. Boston: Element Books, Ltd.

[57] Laszlo, E. (2004). Science and the Akashic field: An integral theory of everything. Rochester, VT: Inner Traditions International.

[58] Brier, S. (2017). Tvrvidenskabsteori. Frederiksberg, Denmark: Samfundslitteratur. (In Danish). 
[59] Brier, S. (2015). Can biosemiotics be a "science" if its purpose is to be a bridge between the natural, social and human sciences? Progress in Biophysics \& Molecular Biology, 119(3), 576587.

[60] Roberts, D. (1973). The existential graphs of Charles S. Peirce. Paris: Mouton.

[61] Habermas, J. (1998). Between facts and norms. Frankfurt am Main: Polity Press.

[62] Taborsky, E. (2006). The nature of the sign as a WFF-a well-formed formula. Conference proceedings from AIP' 06: The Seventh International Conference on Computing Anticipatory Systems. Liège: Belgium. https://doi.org/10.1063/1.2216639.

[63] Ransdell, J. (2017). Is Peirce a phenomenologist? Cybernetics \& Human Knowing, 24(2), 6981.

[64] Apel, K.-O. (1995). Charles Peirce: From pragmatism to pragmaticism. Amherst, MA: Prometheus Books.

[65] Kauffman, S. (2012). From physics to semiotics. In S. Rattasepp \& T. Bennett (Eds.), Gatherings in biosemiotics. Tartu: Tartu University Press.

[66] Popper, K. R. (1972). Objective knowledge: An evolutionary approach. Oxford: Oxford University Press.

[67] Peirce, C. S. (1931-58). Collected Papers vol. I-VIII. C. Hartshorne \& P. Weiss. Cambridge, MA: Harvard University Press.

[68] Brier, S. (2015c). Cybersemiotics and the reasoning powers of the universe: Philosophy of information in a semiotic-systemic transdisciplinary approach. Green Letters, 19, 280-292. http://www.tandfonline.com/doi/full/10.1080/ 14688417.2015.1070684

[69] Mandl, F. \& Shaw, G. (1984/2002). Quantum Field Theory (revised edition). Chichester UK: John Wiley \& Sons.

[70] Hawking, S. (1998). A brief history of time (updated and expanded tenth anniversary ed.). New York, NY: Bantam Books.

[71] Latour, B. (1993). We have never been modern. Cambridge, MA: Harvard University Press.

[72] Zalamea, F. (2012). The logic of continuity. Boston, MA: Docent Press.

\section{About the Author}

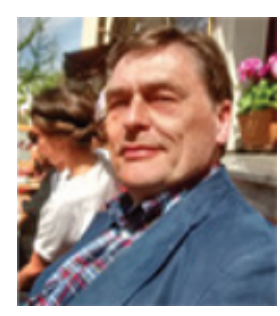

SØren Brier is Professor in the Semiotics of Information, Cognition and Communication Sciences at the Department of International Business Communication at Copenhagen Business School. He is MSc in biology focusing on ethology from U. of Copenhagen, Ph.D. in Philosophy of Information Science at U. of Roskilde and Doctor (Habil) of transdisciplinary Philosophy of science at CBS with the book Cybersemiotics: Why information is not enough, Toronto University of Press (now a Google book and on Kindle, Cybersemiotics.com). Founder and editor in Chief of the interdisciplinary quarterly journal Cybernetics \& Human Knowing, a fellow of the American Society for Cybernetics receiving The Warren McCulloch Award; one of the founders of Int. Ass. For Biosemiotic Studies and on the editorial board of its Journal Biosemiotics as well as the scientific board of The Science of Information Institute and the Foundation of Information Science and of several scientific journals. His been practicing Transcendental meditation and has an interest in Perennial philosophy and its relation to the scientific worldview as well as the pragmaticist and semiotic philosophy of C. S. Peirce and the system science of N. Luhmann. www.cbs.dk/en/staff/sbibc, https://cbs.academia.edu/S 